\title{
Pollution: past, present and future - an Indian perspective
}

\author{
Divyanu Jain* and Ajay K. Jain
}

The term 'pollution' which was hardly in existence a few decades back, has now gained a place in everyday discussions. Presently, not a single living biota, including human beings has remained unaffected from its harmful effects. Pollution is a global problem and according to the World Health Organization, the world's top worst affected cities are in India. Therefore, there is an urgency to give priority to control pollution. The adverse effects of pollutants are affecting human health, economy and progress in various ways. Pollutants alone or in combination with other factors have the potential to cause serious damage to the DNA, cell(s) and organ(s). There is a high possibility that future generations may inherit undesirable traits and suffer from unpredictable consequences. Therefore, there is an urgent need to have reliable and constant monitoring bioassay systems all over the country in order to protect the present biota and future generations from undesirable harmful consequences caused by pollution. In this article, we briefly discuss the various sources of pollutants which are constantly affecting all living biota, including human beings and future perspectives to protect human health.

Keywords: Ecosystem, evolution, harmful pollutants, human health, pollution.

THE term 'pollution' has become a common nomenclature in today's life with a special association with human health. Just a few decades ago, viz. 1970-1980 this term was identified only in the academic and scientific literature, while the term 'ecosystem' has been well recorded for long. The present study aims to highlight the sequential genesis of pollution and its seriousness in our lives, which has totally disturbed the well-established ecosystem. Thus we need to restore the healthy ecosystem and prevent future damages before it is too late.

\section{Realizations in the past}

The seriousness of pollution of River Ganga was realized in 1982-1983. However, knowledge of the probable pollution of other essential components of the environment, namely air, soil, surface and underground water reservoirs, food and noise was lacking. Given the seriousness of this problem, the Government of India (GoI) set up the Department of Environment and assigned it the 'Ganga

Divyanu Jain is in the Department of Obstetrics and Gynecology, Hamamatsu University School of Medicine, Hamamatsu, Shizuoka 431-3192, Japan; Department of Obstetrics and Gynecology and IVF Centre, Jaipur Golden Hospital, Sector-3, Rohini, New Delhi 110085 , India; Ajay K. Jain is in the Department of Obstetrics and Gynecology and IVF Centre, Jaipur Golden Hospital, Sector-3, Rohini, New Delhi 110 085, India; IVF Centre, Muzaffarnagar Medical College, Muzaffarnagar 251001 , India.

*For correspondence. (e-mail: drdivyanujain@gmail.com)
Action Plan' to make the Ganga pollution-free. Further, to support this plan state-level Pollution Control Boards were also set up. In the wake of this problem, the Supreme Court of India has taken steps to ensure the protection and safety of India's precious monument, the Taj Mahal. However, the desired outcomes have not been achieved so far.

\section{Pollution obscured present}

Since the establishment of the Department of Environment and State Pollution Control Boards, the Ganga has not been made pollution-free. Rather, there is no water reservoir, land area or living biota which have not been affected by pollution. To assess the severity of pollutionrelated hazards, the following facts need serious consideration.

(a) According to the global air pollution observatory maintained by the World Health Organization (WHO), 13 of the 20 of the world's most polluted cities are in India, with the capital New Delhi leading the list. The report on the Global Burden of Disease (GBD) has estimated that nearly two million premature deaths occur annually in India due to ambient air pollution ${ }^{1}$. Moreover, it is a widely acknowledged fact that air pollution increases the incidence rates of multiple diseases such as cardiovascular disease, lung cancer, respiratory symptoms, asthma, pregnancy outcomes, infertility, and several other adverse medical conditions (Figure 1$)^{2-7}$. Malhotra et al. ${ }^{8}$ reported 


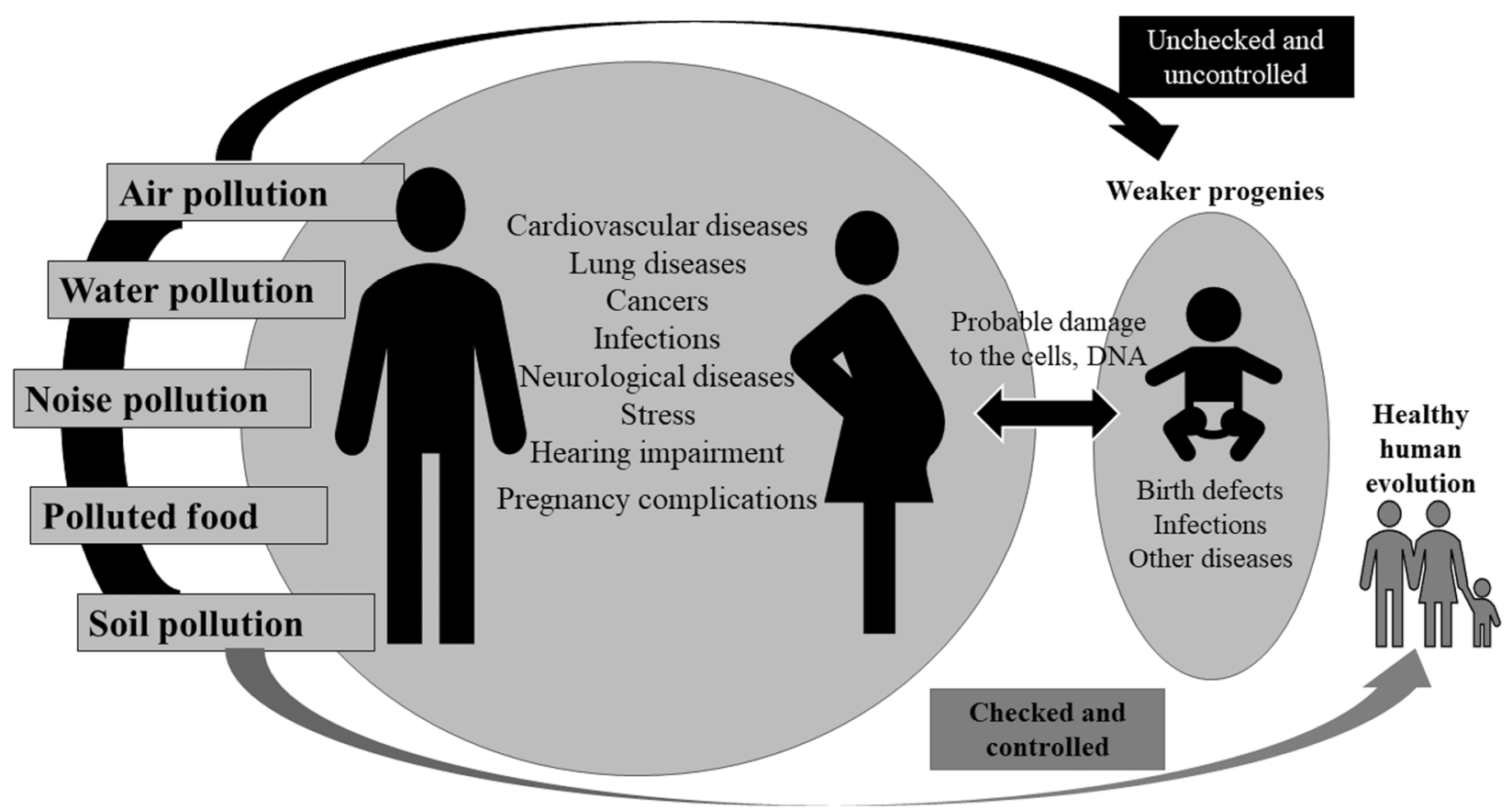

Figure 1. Impact of pollution on human health and evolution.

consistent enhancement in the rate of lung cancer in New Delhi from 1988 to 2012. Additionally, the International Agency for Research on Cancer (IARC) has classified outdoor air pollution as a carcinogen or cancer-causing agent.

(b) During the 19th century when the term 'pollution' had just entered the Indian curriculum, there was only one cancer treatment centre, which was providing cancer treatment to patients from all over the country. Similarly, there were very few cardiac health institutes. During that time, GoI was spending huge resources on family planning because there were very few infertile or childless couples. The increase in disease incidences associated with pollution can be assessed from the fact that in the present scenario, most mid-level cities have fully equipped hospitals/facilities with well-trained and competent manpower to treat such patients. This fact itself proves that during the last few decades there have been some drastic changes in our ecosystem and living style, which are posing a big threat to all living organisms.

(c) It is unreasonable and unscientific that the discussions and planning remain centred on 'air pollution' only. A lot of hue and cry is made when the environment becomes hazy due to air pollution especially with the onset of winter in India; otherwise, it is an ignored subject. The presence of pollutants in water, soil and food seems to be of no significance. Scientifically, this concept is wrong because the entry of a pollutant in the living biota from any source will definitely have a hazardous impact on all the connected life forms. From this point of view, a brief outline of various types of pollution is given below.

\section{Air pollutants - sources and impact}

The major components of air pollution are outdoor and household pollutants, and to smaller extent ozone in the troposphere which is the lowest layer of the atmosphere. The source(s) of outdoor pollutants are fossil fuels, carbon and metallic particles from industrial and automobile emissions, toxic gases, tobacco smoke and chemicals used for various purposes, including ozone. The indoor household pollutants include toxic gases produced from kitchen fuels, commonly used chemicals such as insect repellents and tobacco smoke. Depletion of the ozone layer due to the release of some environmental chemicals also exposes human beings to lethal ultraviolet radiation in sunlight.

In its list of the world's most affected countries due to air pollution, the WHO has ranked China first followed by India 9 . Studies have also indicated that air pollution impacts life expectancy in India ${ }^{10,11}$. According to a study $^{12}$, it has been estimated that one out of every eight deaths in 2017 in the country was associated with air pollution, and it was the second major threat causative to infection load after undernourishment in 2016.

\section{Water pollution - worrying trends}

Water is one of our most abundant natural resources which is essential to sustain life on earth. It has been estimated that only $0.26 \%$ of the earth's water is available for human consumption ${ }^{13}$. Access to safe water and sanitation, and sound management of freshwater ecosystems 
are essential to human health, environmental sustainability and economic prosperity ${ }^{14}$.

According to a report, $70 \%$ of available water in India is polluted ${ }^{15}$. It has been further estimated that in India, $36 \%$ of the urban and $65 \%$ of the rural population do not have access to safe drinking water and are consuming contaminated water ${ }^{16}$. Pollution of natural water starts from the point of origin itself, when it comes down to the earth in the form of rain along with pollutants present in the atmospheric air. Further, in the course of flowing on the surface, it gets enriched with more pollutants which are introduced in the aquatic system by different ways such as weathering of rocks, leaching of soils, anthropogenic activities such as mining, processing, discharge of untreated waste of industries, agriculture and human-used products of metal-based materials ${ }^{17,18}$. According to a report of $\mathrm{CAG}$, sewage and industrial waste discharged constitute the main polluting sources of aquatic systems in the country and of all the wastewater generated, only about $10 \%$ is treated before being discharged into the water bodies ${ }^{19}$. Approximately $30 \%$ of the garbage generated is not collected, the remaining $70 \%$ collected is dumped in landfills or the space available in nearby habitats, which is washed away and mixes with nearby water bodies during heavy precipitation in the monsoon season $^{20}$. Only $18 \%$ of the collected garbage is treated. The amount of sewage generated every day is 38 billion litres and installed capacity to treat wastewater is around 12 billion litres. Thus the remaining 26 billion litres of sewage is dumped into rivers on a daily basis ${ }^{19}$. Due to consumption of contaminated drinking water, the human population suffers from various types of waterborne diseases as summarized below.

\section{Waterborne bacterial diseases}

Cholera is caused by Vibrio cholerae through contaminated water. This bacterium produces toxins in the digestive tracts which cause watery diarrhoea, nausea, vomiting and may lead to dehydration and renal failure. Campylobacter jejuni is the causal pathogen for diarrhoea, affecting $4-15 \%$ of the world's population. Shigellosis is another bacterial disease caused by Shigella. It affects the digestive tract of humans and damages the intestinal lining. Salmonellosis infection occurs in the intestinal tract by the ingestion of Salmonella and results in the intestinal inflammation.

\section{Waterborne viral diseases}

Hepatitis is one of the most common viral diseases due to contaminated water and infects the liver leading to jaundice, loss of appetite, fatigue, discomfort and high fever. If it persists for long, it may even result in death. Encephalitis is another viral inflammatory disease spread by the infected mosquitoes. Culex mosquitoes lay their eggs in contaminated water. Generally infected people do not show any symptoms, but some symptoms include headache, high fever, muscle stiffness, and convulsions, which may lead to coma and paralysis. Poliomyelitis is also a waterborne disease due to the Poliovirus affecting children in developing countries and, if severe, may sometimes cause paralysis. Gastroenteritis is caused by different viruses including Rotavirus, Adenovirus, Calcivirus, and Norwalk virus. The sickness can be dangerous among infants, young children and disabled persons. Vaccines are available for hepatitis and polio, but not for encephalitis.

\section{Waterborne parasitic diseases}

Malaria is one of the most common diseases in India caused by Plasmodium. The infection causes severe damage to the liver. Cryptosporidiosis is a parasitic disease caused by Cryptosporidium parvum. It is a worldwide disease and symptoms are similar to those of diarrhoea. Cryptosporidium is resistant to disinfection and affects the immune system. Galloping amoebiasis is caused by Entamoeba histolytica and affects the stomach lining. The infection occurs when cysts found in contaminated water are swallowed causing symptoms such as fever, chills, and watery diarrhoea. Giardiasis is caused by Giardia lamblia, which damages the cells of the intestinal lining.

\section{Agriculture-associated pollution}

The use of chemicals such as fertilizers and pesticides has increased tremendously during the last few decades. A major quantity of these chemicals enters into the food products consumed by humans, cattle providing dairy products, and underground and surface water bodies. The burning of agricultural waste also introduces huge quantities of pollutants in the air and environment. Brainerd and Menon $^{21}$ have reported that exposure to such pollutants in women during conception followed by delivery increases infant mortality, and affects height and weight for the corresponding age. Several studies have reported negative health effects such as increase in infant mortality, enhanced asthma cases, and pre-term births due to wildfires in Indonesia ${ }^{22,23}, \mathrm{USA}^{24}$ and Australia ${ }^{25}$.

\section{Noise pollution}

Ears are a hypersensitive part of the human body that perform vital functions in the defence mechanism. According to a study ${ }^{26}$, sounds affect our state of mind differently depending on whether they are pleasant or not. In this respect, the major findings of some other important studies are alarming. 
Münzel et al. ${ }^{27}$ found that stress and disturbance during sleep time due to noise pollution may lead to cardiovascular disease. Harding et al. ${ }^{28}$ estimated that the exposure to noise pollution above levels recommended by WHO led to additional 542 cases of heart attack, 788 cases of stroke and 1169 cases of dementia in the UK in a single year. The study concluded that these health impacts together caused a burden of $£ 1.09$ billion ( $€ 1.34$ billion). Schmidt et $a l .{ }^{29}$ reported that repeated exposure to aircraft noise can lead to constant stress, permanently high blood pressure, and thereby leading to cardiovascular disease. Another study highlighted that school-going children exposed to noise from aircraft and road traffic experience learning and comprehension difficulties ${ }^{30}$. Tiesler et $a l .{ }^{31}$ observed hyperactivity and behavioural problems in children exposed to high levels of noise pollution. According to WHO estimates, $10 \%$ of the global population is currently exposed to noise levels that could lead to hearing impairment ${ }^{32}$. Not surprisingly, it has been reported that the quality of life increases with a decrease in noise levels ${ }^{33}$. The study also revealed that health-related quality of life was highest in a quiet rural location. In India, the problem of noise pollution has already reached alarming levels. Firdaus and $\mathrm{Ahmad}^{34}$ found that noise pollution is assuming serious proportions in Delhi. Some studies have warned that the noise level in metropolitan cities has exceeded the specified standard limits and may be responsible for the rising incidence of deafness among people ${ }^{35}$.

\section{Heavy metal-associated pollution}

Minor elements such as copper, based on their requirement, influence the biological pathways through metalbinding proteins and enzymatic reactions in living organisms. These elements play a vital role in human physiology. On the other hand, some heavy metals such as cadmium, lead, mercury and arsenic have been classified as pollutants given their bio-toxicity ${ }^{36,37}$. The source of their contamination is natural, industrial, domestic and medicinal. Heavy metal-associated pollution has been found to affect flora and fauna ${ }^{38}$, impairing the functions of enzymes at the cellular level and thereby causing damage to the organ systems such as nervous, hemopoietic, renal, cardiovascular and reproductive system ${ }^{37,39-42}$.

\section{Effect of pollution on food}

Food products may get contamination of pollutants from various sources. Food (e.g. crops, fruits, vegetables) grown in polluted soils, untreated waste-accumulated fields or areas with polluted groundwater; irrigation with polluted water; growing of food crops in areas with polluted air; agricultural treatments with pesticides, insecticides, and/or herbicides; agricultural application of sewage sludge and/or polluted fertilizers, e.g. ash from power plants; consumption of polluted water and/or food by fish or other animals; food processing, packaging, and handling; and propagation and concentration of pollutants through the food chain.

Thus, any source which pollutes the air, water and soil may further become a source of food pollution and thereby reach the human body. Pollutants that have the potential to affect human cell(s) or systems can also affect other biota of the chain in unnoticed ways.

\section{Synergistic effect of electromagnetic field radiation and pollutants}

In addition to the pollutants from various sources, human populations are constantly being exposed to radiation in the form of electromagnetic fields (EMFs) which are surrounding us from various sources like electrical appliances, microwave ovens, cell phones, mobile base stations, Wi-Fi connections, etc. It has been reported that EMFs may affect the human system in various ways ${ }^{43,44}$. Synergistic action of EMFs along with other chemicals like pesticides and heavy metals has been found to affect human systems at DNA and cellular level ${ }^{45,46}$. Exposure to magnetic resonance imaging and EMFs from mobile phones have been observed to release mercury from dental amalgam fillings ${ }^{47}$.

\section{Future - are we prepared?}

At present, pollution has already reached an alarming stage in just a few decades. Pollutants alone or in synergistic action are affecting the whole ecosystem, including humans in various ways. Some of the damages may cause permanent heritable changes in the genome of living organisms, which may be disastrous. Further, climate change that is also inter-related with pollution may alter geological factors, which may further affect the environmental conditions.

It is apparent from the above discussion that pollution has become the most serious problem of today's advanced world. It is time to solve this problem in a scientific manner. First, there is a need to consider this as the 'global and national crisis', and not as a local, occasional or seasonal situation. The problem cannot be solved only by framing laws, rules, regulations and guidelines, as is evident from the audit study report of the Central Pollution Control Board ${ }^{48}$, conducted on automobile pollution check centres in Delhi. It was found that manpower at most of the centres was poorly trained and unaware of protocols for testing; the equipment was mostly not well maintained and was rarely properly calibrated. The auditing team also documented instances of unauthorized officials passing vehicles, and software being used to generate dummy measurements. The auditing report has 
suggested for greater scrutiny of the pollution centres. Thus, the desired outcomes of the 'Automobiles Pollution Control Certificate' law could not be achieved because of inadequacy in the implementation itself. The best way to control pollution is to develop and implement scientific methods to restrict the release of pollutants at the source itself. This needs the dedicated involvement of scientists and experts from various disciplines (biotechnologists, medical professionals, engineers, sociologists), who could jointly work out the strategy in a scientific manner. This was proven to be possible during the recent nationwide lockdown imposed in India from 22 March 2020 onwards. This lockdown halted almost all industrial activities and mass transportation, which prevented the release of pollutants in the environment and thereby a significant reduction in pollution levels in 88 cities across the country ${ }^{49,50}$. Further reduction in pollution levels was evident from the visuals of snow-covered peaks of the Himalaya from Saharanpur which is at a distance of about $200 \mathrm{~km}$; this was possible only because of the absence of pollutants in the environment ${ }^{51}$.

No advancement, growth and prosperity is possible without modern industrialization and technology. However, simultaneous safe exposure and preservation of the ecosystem are of prime importance. There is a need to have effective constant monitoring of the biota and ecosystems to protect and preserve the same from the consistent harmful impact of pollutants causing massive damage to the level of DNA. Such damage may be irreparable and might lead to the transmission of undesirable traits in the future progenies. One of the basic principles of science mentions that, 'Nothing is impossible but needs a definite goal which can be achieved by systematic planning and execution', which seems valid in this situation. The target can be achieved by collective positive efforts of every concerned individual.

Disclosure statement. The authors declare no conflict of interest.

1. Wang, H. et al., Global, regional, and national life expectancy, allcause mortality, and cause-specific mortality for 249 causes of death, 1980-2015: a systematic analysis for the Global Burden of Disease Study 2015. Lancet, 2016, 388, 1459-1544.

2. Williams, R., Brook, R., Bard, R., Conner, T., Shin, H. and Burnett, R., Impact of personal and ambient-level exposures to nitrogen dioxide and particulate matter on cardiovascular function. Int. J. Environ. Health Res., 2012, 22, 71-91.

3. Pope, C. A. et al., Lung cancer, cardiopulmonary mortality, and long-term exposure to fine particulate air pollution. J. Am. Med. Assoc., 2002, 287, 1132-1141.

4. Nhung, N. T. T., Schindler, C., Dien, T. M., Probst-Hensch, N., Perez, L. and Künzli, N., Acute effects of ambient air pollution on lower respiratory infections in Hanoi children: an eight-year time series study. Environ Int., 2018, 110, 139-148.

5. Goodman, J. E., Zu, K., Loftus, C. T., Tao, G., Liu, X. and Lange, S., Ambient ozone and asthma hospital admissions in Texas: a time-series analysis. Asthma Res. Pract., 2017, 3.
6. Ha, S. et al., Ambient air pollution and the risk of pregnancy loss: a prospective cohort study. Fertil. Steril., 2018, 109, 148-153.

7. Khreis, H., Kelly, C., Tate, J., Parslow, R., Lucas, K. and Nieuwenhuijsen, M., Exposure to traffic-related air pollution and risk of development of childhood asthma: a systematic review and meta-analysis. Environ. Int., 2017, 100, 1-31.

8. Malhotra, R. K., Manoharan, N., Nair, O., Deo, S. and Rath, G. K., Trends in lung cancer incidence in Delhi, India 1988-2012: age-period-cohort and join point analyses. Asian Pac. J. Cancer Prev., 2018, 19, 1647-1654.

9. Vaughan, A., China tops WHO list for deadly outdoor air pollution. The Guardian, 2016; https://www.theguardian.com/environment/ 2016/sep/27/more-than-million-died-due-air-pollution-china-one-year

10. Ghude, S. D. et al., Premature mortality in India due to PM2.5 and ozone exposure. Geophys. Res. Lett., 2016, 43, 4650-4658.

11. Apte, J. S., Brauer, M., Cohen, A. J., Ezzati, M. and Pope, C. A., Ambient PM2.5 reduces global and regional life expectancy. Environ. Sci. Technol. Lett., 2018, 5, 546-551.

12. Dandona, L. et al., Nations within a nation: variations in epidemiological transition across the states of India, 1990-2016 in the Global Burden of Disease Study. Lancet, 2017, 390, 2437-2460.

13. Kudesia, V. P., Water Pollution, Pragati Prakashana, Meerut, 1980.

14. UN, Progress towards the Sustainable Development Goals E/2017/66. Report of the Secretary-General, United Nations, https://unstats.un.org/sdgs/files/report/2017/secretary-general-sdgreport-2017-EN.pdf

15. Agarwal, A., Chopra, R. and Sharma, K., The state of India's environment-1982: a citizens' report. Centre for Science and Environment, New Delhi, 1982.

16. World Health Organization, WHO Guidelines for Drinking Water Quality (Vol. 2), Health Criteria and other Supporting Informations, WHO, Geneva, 2004, 2nd edn, pp. 231-233.

17. Comptroller and Auditor General of India, Performance audit of water pollution in India. CAG Report No. 21. of 2011-12, New Delhi, 2012.

18. Mixed traffic in recycle path. The Times of India, Ahmadabad, 2014.

19. Adeyeye, E. I., Determination of trace heavy metals in Illisha africana fish and in associated water and soil sediments from some fish ponds. Int. J. Environ. Stud., 1994, 45, 231-238.

20. Adefem, O. S. and Awokunmi, E. E., Investigation of some physico-chemical parameters and determination of heavy metals in selected water samples from Itaogbolu area of Akure, Ondo State, Nigeria. Orient. J. Chem., 2009, 25, 295-298.

21. Brainerd, E. and Menon, N., Seasonal effects of water quality: the hidden costs of the Green Revolution to infant and child health in India. J. Dev. Econ., 2014, 107, 49-64.

22. Jayachandran, S., Air quality and early-life mortality: evidence from Indonesia's wildfires. J. Hum. Resour., 2009, 44, 916-954.

23. Frankenberg, E., McKee, D. and Thomas, D., Health consequences of forest fires in Indonesia. Demography, 2005, 42, 109-129.

24. Holstius, D. M., Reid, C. E., Jesdale, B. M. and Morello-Frosch, R., Birth weight following pregnancy during the 2003 southern California wildfires. Environ. Health Perspect., 2012, 120, 1340 1345.

25. O'Donnell, M. H. and Behie, A. M., Effects of wildfire disaster exposure on male birth weight in an Australian population. Evol. Med. Public Health, 2015, 2015, 344-354.

26. Andringa, T. C. and Lanser, J. J. L., How pleasant sounds promote and annoying sounds impede health: a cognitive approach. Int. J. Environ. Res. Public Health, 2013, 10, 1439-1461.

27. Münzel, T., Gori, T., Babisch, W. and Basner, M., Cardiovascular effects of environmental noise exposure. Eur. Heart J., 2014, 35.

28. Harding, A. H., Frost, G., Tan, E., Tsuchiya, A. and Mason, H., The cost of hypertension-related ill-health attributable to environmental noise. Noise \& Health, 2013, 15, 437-445. 
29. Schmidt, F. P. et al., Effect of nighttime aircraft noise exposure on endothelial function and stress hormone release in healthy adults. Eur. Heart J., 2013, 34

30. Van Kamp, I. and Davies, H., Noise and health in vulnerable groups: a review. Noise \& Health, 2013, 15, 153-159.

31. Tiesler, C. M. T. et al., Exposure to road traffic noise and children's behavioural problems and sleep disturbance: results from the GINIplus and LISAplus studies. Environ. Res., 2013, 123, 1-8.

32. Oishi, N. and Schacht, J., Emerging treatments for noise-induced hearing loss. Expert Opin. Emerg. Drugs, 2011, 16, 235-245.

33. Shepherd, D., Welch, D., Dirks, K. N. and McBride, D., Do quie areas afford greater health-related quality of life than noisy areas? Int. J. Environ. Res. Public Health, 2013, 10, 1284-1303.

34. Firdaus, G. and Ahmad, A., Noise pollution and human health: a case study of Municipal Corporation of Delhi. Indoor Built. Environ., 2010, 19, 648-656.

35. Bhargawa, G., Development of India's Urban and Regional Planning in 21st Century, Gian Publishing House, New Delhi, 2001, pp. 115-116.

36. Kordas, K., Lönnerdal, B. and Stoltzfus, R. J., Interactions between nutrition and environmental exposures: effects on health outcomes in women and children. J. Nutr., 2007, 137, 2794-2797.

37. Indian National Science Academy, Hazardous metals and minerals pollution in India: sources, toxicity and management - a position paper, 2011; http://citeseerx.ist.psu.edu/viewdoc/download?doi= 10.1.1.458.8609\&rep=rep1\&type $=$ pdf

38. Gbaruko, B. C. and Friday, O. U., Bioaccumulation of heavy metals in some fauna and flora. Int. J. Environ. Sci. Technol., 2007, 4, 197-202.

39. Sakai, T., Biomarkers of lead exposure. Ind. Health, 2000, $\mathbf{3 8}$ 127-142.

40. Flora, S. J. S., Flora, G. and Saxena, G., Environmental occurrence, health effects and management of lead poisoning. Lead, 2006, 158-228.

41. Bellinger, D. C., Childhood lead exposure and adult outcomes. J. Am. Med. Assoc., 2017, 317, 1219-1220.
42. Kumar, B. D. and Krishnaswamy, K., Detection of sub-clinical lead toxicity in monocasters. Bull. Environ. Contam. Toxicol., 1995, 54, 863-869.

43. Carpenter, D. O., Human disease resulting from exposure to electromagnetic fields. Rev. Environ. Health, 2013, 28, 159-172.

44. Havas, M., Radiation from wireless technology affects the blood, the heart, and the autonomic nervous system. Rev. Environ. Health, 2013, 28, 75-84.

45. Ferguson, L. R., Chronic inflammation and mutagenesis. Mutat. Res. - Fundam. Mol. Mech. Mutagen., 2010, 690, 3-11.

46. Oliveira, H., Lopes, T., Almeida, T., Pereira, M. D. L. and Santos, C., Cadmium-induced genetic instability in mice testis. Hum. Exp. Toxicol., 2012, 31, 1228-1236.

47. Mortazavi, S. M. J. et al., Mercury release from dental amalgam restorations after magnetic resonance imaging and following mobile phone use. Pak. J. Biol. Sci., 2008, 11, 1142-1146.

48. Central Pollution Control Board, Auditing of authorised vehicular checking centers in Delhi. Ministry of Environment, Forests and Climate Change, Government of India, 2013; http://164.100. 47.5/committee_web/ReportFile/19/103/316_2018_8_14.pdf

49. Sharma, S., Zhang, M., Anshika, Gao, J., Zhang, H. and Kota, S. H., Effect of restricted emissions during COVID-19 on air quality in India. Sci. Total Environ., 2020, 728.

50. Mahato, S., Pal, S. and Ghosh, K. G., Effect of lockdown amid COVID-19 pandemic on air quality of the megacity Delhi, India. Sci. Total Environ., 2020, 730.

51. Bhatia, I., Saharanpur wakes up to Himalayas, visible from town after 30 years as AQI dips below 50. The Times of India, Meerut, 30 April 2020; https://timesofindia.indiatimes.com/city/meerut/ saharanpur-wakes-up-to-himalayas-visible-from-town-after-30years-as-aqi-dips-below-50/articleshow/75465589.cms

Received 15 June 2020; revised accepted 14 July 2020

doi: $10.18520 / \mathrm{cs} / \mathrm{v} 119 / \mathrm{i} 7 / 1087-1092$ 